\title{
BMJ Open Bidirectional association between migraine and rheumatoid arthritis: two longitudinal follow-up studies with a national sample cohort
}

\author{
Yoo Hwan Kim (D) , ${ }^{1}$ Jung Woo Lee, ${ }^{2}$ Yerim Kim, ${ }^{3}$ Jong Seok Bae, ${ }^{3}$ Yeo Jin Kim, ${ }^{4}$ \\ Chanyang Min, ${ }^{5,6}$ Hyo Geun Choi (D) 5,7
}

To cite: Kim YH, Lee JW, Kim Y, et al. Bidirectional association between migraine and rheumatoid arthritis: two longitudinal followup studies with a national sample cohort. BMJ Open 2021;11:e046283. doi:10.1136/ bmjopen-2020-046283

- Prepublication history and supplemental material for this paper is available online. To view these files, please visit the journal online (http://dx.doi org/10.1136/bmjopen-2020046283).

Received 26 October 2020 Revised 10 March 2021 Accepted 26 April 2021
Check for updates

(c) Author(s) (or their employer(s)) 2021. Re-use permitted under CC BY-NC. No commercial re-use. See rights and permissions. Published by BMJ.

For numbered affiliations see end of article.

Correspondence to

Dr Hyo Geun Choi;

pupen@naver.com

\section{ABSTRACT}

Objective To investigate the bidirectional association between migraine and rheumatoid arthritis (RA).

Design Two longitudinal follow-up studies.

Setting Data collected from a national cohort between 2002 and 2013 by the Korean National Health Insurance Service-Health Screening Cohort.

Participants In cohort 1, matching resulted in the inclusion of 31589 migraine patients and 126356 control I participants. In cohort 2, matching resulted in the inclusion of 9287 RA patients and 37148 control II participants.

Primary and secondary outcome measures The HRs for RA in patients with migraine (cohort 1) and migraine in patients with RA (cohort 2) were analysed using stratified Cox proportional hazard models after adjusting for autoimmune disease, Charlson Comorbidity Index scores without rheumatoid diseases, obesity (body mass index), smoking and history of alcohol intake. Subgroup analyses stratified by age, sex, income and region of residence were also performed.

Results The incidence of RA in the migraine group (2.0\% $(640 / 31589))$ was higher than that in the control I group (1.4\% (1709/126 356), $p<0.001)$. The adjusted HR for $\mathrm{RA}$ in the migraine without aura group was 1.48 (95\% $\mathrm{Cls}=1.34$ to $1.63, \mathrm{p}<0.001$ ).

The incidence of migraine in the RA group $(6.4 \%$ (590/9287)) was higher than that in the control II group (4.6\% (1721/37 148), $\mathrm{p}<0.001)$. The adjusted HR for migraine without aura in the RA group was 1.35 (95\% $\mathrm{Cl}=1.23$ to $1.49, \mathrm{p}<0.001$ ).

Conclusion Migraine increases the risk of RA, and RA is also associated with an increased risk of migraine.

\section{INTRODUCTION}

Migraine is a primary headache characterised by neurological symptoms and recurrent episodic attacks with various triggers. ${ }^{1}$ The complete pathophysiological mechanism is still unknown, but several causes of migraine have been suggested. A variety of factors, including those involving the central nervous system, the immune system, inflammation, genetics and vascular ischemia, can
Strengths and limitations of this study

- The strength of this study is that it is an evaluation of the bidirectional association between migraine and rheumatoid arthritis using a large Korean sample population with a long follow-up period.

- Owing to the large number of participants, we could match enough control participants in a 1:4 ratios, maintaining the statistical power in the subgroup analyses.

- One limitation is that confounding variables related to socioeconomic factors, such as occupation, physical inactivity, diet and nutrition, were not available, as this study evaluated the associations using medical claim codes.

contribute to the development of migraine attacks. $^{2}$ The main mechanisms that have been suggested to underlie the development of a migraine are hypothalamic activation, alterations in thalamocortical circuits, altered brain connectivity, brainstem activation, cortical spreading depression and the release of calcitonin gene-related peptide (CGRP). ${ }^{34}$ The clinical features of a migraine attack are divided into the premonitory phase, the aura phase, the headache phase and the postdrome phase based on hormonal and nervous system changes. ${ }^{3}$

Rheumatoid arthritis (RA) is a chronic systemic inflammatory disease involving synovitis in multiple joints. There are several causative factors involved in the pathophysiology of RA, including genetic, environmental and immunological factors. ${ }^{5-7}$ The inflammatory responses in RA are not limited to synovitis and can become systemic. RA has been reported to be associated with multiple systemic diseases, including cardiovascular disease, lung disease and neuropsychiatric disease. $^{8}$ 
Recently, RA has been found to be associated with migraine. Only a few studies have reported an association between migraine and RA. Wang et at published a longitudinal study showing that patients with migraines had a high risk of developing RA, but the results were unidirectional. One study reported that patients with severe headaches or migraines were much more likely to develop RA than their counterparts, but the interpretation of those results was limited because of the use of a cross-sectional study design. ${ }^{10}$ In a questionnaire study assessing the prevalence of migraines in patients with rheumatic disease, there was little difference between the group with rheumatic diseases and the control group. ${ }^{11}$ It has been suggested that the shared pathophysiological mechanisms involving inflammatory processes and autoimmune responses explain the association between migraine and RA. ${ }^{911}$

Based on the common pathophysiologic mechanisms of inflammation, vascular endothelial cells and the immune system between migraine and RA, we hypothesised that there might be a bidirectional association between migraine and RA. ${ }^{12-15}$ Two longitudinal follow-up studies were designed to test this hypothesis. In each study, the control group was matched with the study group according to age, sex, income and region of residence. To exclude potential confounding effects, the Charlson Comorbidity Index (CCI), body mass index (BMI), smoking, alcohol consumption and autoimmune disease histories were used for adjustment.

\section{MATERIALS AND METHODS}

\section{Study population and data collection}

This national cohort study used data from the Korean National Health Insurance Service-Health Screening Cohort (NHIS-HEALS) covering the period from 1 January 2002 through 31 December 2013. Written informed consent was not required because the data were sorted and analysed using random numbers for research purposes. A detailed description of these data can be found in online supplemental file $1 .^{16}$

\section{Patients and public involvement}

No patients or public were involved in this study.

\section{Participant selection}

The Korean NHIS-HEALS study included 514866 individuals with 497931549 medical claim codes. Two cohorts were constructed.

\section{Cohort 1: risk for incident RA in persons with migraine}

We enrolled those with migraine, as defined by the International Statistical Classification of Diseases and Related Health Problems version 10 (ICD-10) code G43. Migraine was classified as migraine with aura and migraine without aura (ICD-10: G431), as in our previous studies. ${ }^{1718}$ Migraine was identified if participants were diagnosed with these conditions at least two times. ${ }^{19}$ The case definition included two separate visits associated with a diagnosis of migraine, with the first visit selected as the index date. The migraine group was matched 1:4 with the control I group, which was composed of individuals who were not diagnosed with migraine from 2002 to 2013. Matching was based on age group, sex, income group and region of residence. To avoid selection bias, the control I participants were arranged using random numbers and then selected from top to bottom. Assuming that the matched control I participants were involved at the same time as each matched migraine participant, we set the index date for both the migraine participant and the matched control participants as the date of the diagnosis of migraine. Control participants who died before the index date were replaced by other control participants. Participants with histories of RA prior to the index date were excluded from both the migraine and control groups. After matching the participants in cohort 1, we analysed the occurrence of RA in patients with migraine with aura and their controls and in patients with migraine without aura and their controls.

\section{Cohort 2: risk for incident migraine in persons with RA}

RA was defined as in previous studies that reported the prevalence and incidence of RA in Korea. ${ }^{20}{ }^{21} \mathrm{RA}$ was selected based on the relevant ICD-10 codes (M05 or M06) and a prescription for a biologic agent or any disease-modifying antirheumatic drug (DMARD). RA was identified if participants were diagnosed with these conditions at least two times. ${ }^{19}$ The case definition included two separate visits associated with a diagnosis of RA and medical treatment for RA, with the first visit selected as the index date. The RA group was matched 1:4 with the control II group, which was composed of individuals who were not diagnosed with RA from 2002 to 2013. Matching was based on age group, sex, income group and region of residence. To avoid selection bias, the control II participants were arranged using random numbers and then selected from top to bottom. Assuming that the matched control II participants were involved at the same time as each matched RA participant, we set the index date for both the RA patients and their matched controls as the date of the RA diagnosis. Control participants who died before the index date were replaced by other control participants. Participants with a history of migraine prior to the index date were excluded from both the RA and control groups. After matching in cohort 2, we analysed the occurrence of migraine with/without aura in patients with RA.

\section{Variables}

The age groups were classified using 5-year intervals: $40-44,45-49,50-54 \ldots$ and $>80$ years. A total of nine age groups were designated. The income groups were divided into five classes (class 1 (lowest income)-class 5 (highest income)). The region of residence was divided into 16 areas according to the administrative district. These regions were regrouped into urban (Seoul, Busan, Daegu, 
Incheon, Gwangju, Daejeon and Ulsan) and rural (Gyeonggi, Gangwon, Chungcheongbuk, Chungcheongnam, Jeollabuk, Jeollanam, Gyeongsangbuk, Gyeongsangnam and Jeju) areas. ${ }^{19}$ Tobacco smoking was categorised according to the current smoking state (nonsmoker, ex-smoker and current smoker). Alcohol consumption was categorised according to the frequency $(<1$ time a week and $\geq 1$ time a week). Obesity was measured using BMI $\left(\mathrm{kg} / \mathrm{m}^{2}\right)$ and categorised as $<18.5$ (underweight), $\geq 18.5-<23$ (normal), $\geq 23-<25$ (overweight), $\geq 25-<30$ (obese I) and $\geq 30$ (obese II) according to the Regional Office for the Western Pacific 2000. ${ }^{1622}$

Autoimmune disease was defined as psoriasis (B02), systemic lupus erythematosus (M32), systemic sclerosis (M34), Sjogren syndrome (M350), dermatopolymyositis (M33), and polyarteritis nodosa and related conditions (M30). The CCI was calculated for 16 comorbidities, excluding rheumatic diseases, and analysed as a continuous variable $(0$ (no comorbidity) through 28 (multiple comorbidities) $).{ }^{23}$

\section{Statistical analyses}

In cohorts 1 and $2, \chi^{2}$ tests were used to compare demographic and general characteristics between groups within each study.

In cohort 1 , a stratified Cox proportional hazards model was used to estimate the HR for RA (dependent variable) in patients with migraine (independent variable). In cohort 2, another stratified Cox proportional hazards model was applied to estimate the HR for migraine (dependent variable) in patients with RA (independent variable). Age, sex, income and region of residence were used to stratify the participants, and the $95 \%$ CIs were calculated. In the adjusted model, we adjusted for CCI scores (continuous variable), BMI group, smoking, alcohol consumption and autoimmune disease history (categorical variable). The Kaplan-Meier method and the log-rank test were used for the survival analysis.

For the subgroup analyses, we divided the participants by age and sex ( $<60$ years and $>60$ years; men and women). Other subgroup analyses were performed by income (low (groups 1-3) and high (groups 4 and 5)) and region of residence (urban and rural). The cut-off value for age was determined by the median value. Additionally, we analysed HRs according to the presence of an aura.

Our data were analysed using two-tailed tests ( $p$ value $<0.05)$. The results were statistically analysed using SPSS V.22.0 (IBM) and SAS V.9.4 (SAS Institute).

\section{RESULTS \\ Cohort 1}

The results of the 1:4 matching yielded 31589 migraine patients and 126356 control I participants (table 1 and figure 1). The mean follow-up time from the index date to the last date (31 December 2013) or date of death was approximately the same in both the migraine ( 76.3 months, $\mathrm{SD}=36.9)$ and control I groups (76.0 months, $\mathrm{SD}=37.1)$. The interval from the index date to the diagnosis of RA was 41.8 months $(\mathrm{SD}=31.5)$ in the migraine group and 37.1 months $(\mathrm{SD}=31.3)$ in the control I group.

The incidence of RA was higher in the migraine group $(2.0 \%(640 / 31589))$ than in the control I group $(1.4 \%$ (1709/126 356), $\mathrm{p}<0.001$, table 1$)$. The general characteristics (age, sex, income and region of residence) of the participants were the same after matching $(\mathrm{p}=1.000)$. The adjusted HR for RA in the migraine without aura group was 1.48 (95\% $\mathrm{CI}=1.34$ to 1.63 , $\mathrm{p}<0.001$, table 2 ; figure 2 ). The adjusted HR for RA in the migraine with aura group was $1.23(95 \% \mathrm{CI}=0.91$ to $1.67, \mathrm{p}=0.183)$.

\section{Cohort 1}

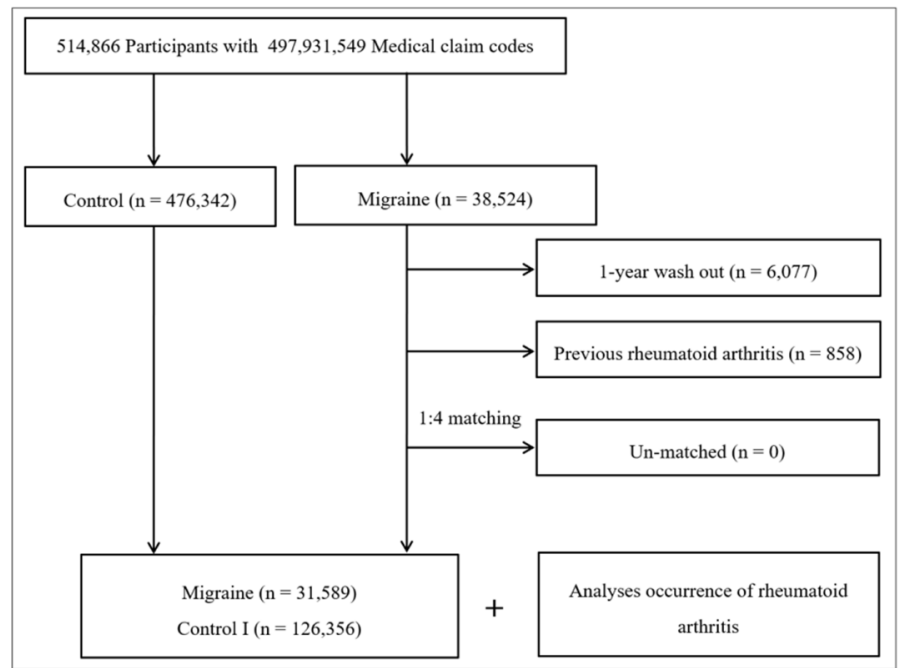

\section{Cohort 2}

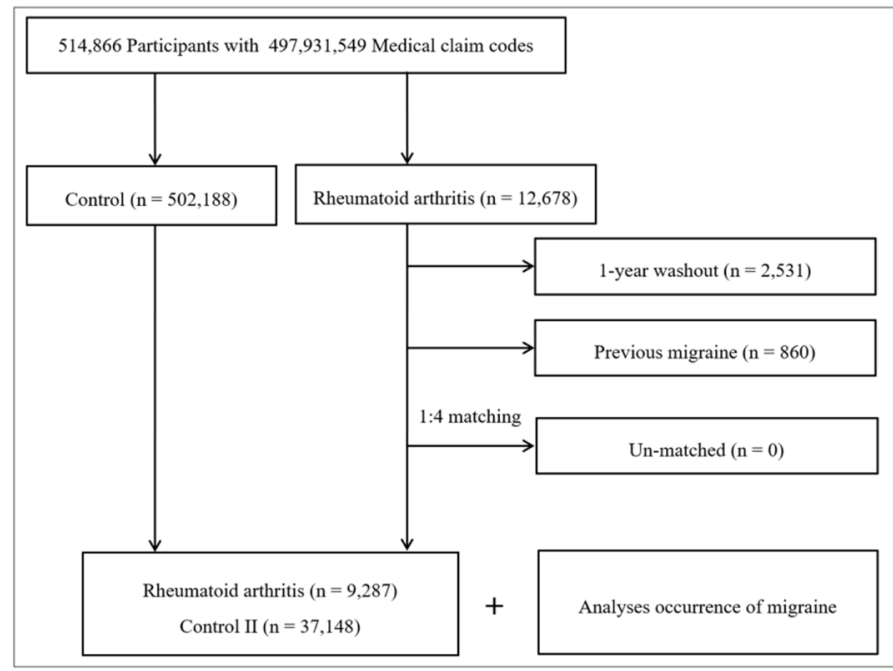

Figure 1 Schematic illustration of the participant selection process that was used in this study. Cohort 1: Of 514866 participants, 31589 migraine patients were matched with 126356 control I participants for age group, sex, income group and region of residence. Cohort 2: Of 514866 participants, 9287 rheumatoid arthritis patients were matched with 37148 control II participants for age group, sex, income group and region of residence. 
Table 1 General characteristics of the participants

\section{Cohort 1}

\section{Characteristics}

Number (n)

Age (years)

\begin{tabular}{cc}
\hline $40-44$ & 1 \\
\hline $45-49$ & 477 \\
$50-54$ & 573 \\
$55-59$ & 46 \\
$60-64$ & 4 \\
$65-69$ & 4 \\
$70-74$ & 3 \\
$75-79$ & 18 \\
$>80$ & 797 \\
Sex &
\end{tabular}

Male

Female

Income

1 (lowest)

2

3

4

5 (highest)

Region of residence

Urban

Rural

$\mathrm{CCl}(\text { score })^{\star}$

0
1
2
$\geq 3$
$B M I$

BMI

$\begin{array}{ll}<18.5 \text { (underweight) } & 771 \\ \geq 18.5-<23 \text { (normal) } & 114 \\ \geq 23-<25 \text { (overweight) } & 8 \\ \geq 25-<30 \text { (obese I) } & 998 \\ \geq 30 \text { (obese II) } & 947\end{array}$

Smoking

Non-smoker or ex-

smoker

Current smoker

Drinking alcohol

$<1$ time a week

$\geq 1$ time a week

Autoimmune disease

Migraine

Migraine (n, \%)

31589

1528 (4.8)

$4776(15.1)$

$5730(18.1)$

4666 (14.8)

$4423(14.0)$

4446 (14.1)

3417 (10.8)

1806 (5.7)

797 (2.5)

10169 (32.2)

21420 (67.8)

5692 (18.0)

4698 (14.9)

5235 (16.6)

6574 (20.8)

9390 (29.7)

12225 (38.7)

19364 (61.3)

31054 (98.3)

$56(0.2)$

$55(0.2)$

424 (1.3)

$771(2.4)$

$11438(36.2)$

8450 (26.8)

9983 (31.6)

947 (3.0)

28146 (89.1)

3443 (10.9)

26747 (84.7)

4842 (15.3)

8119 (25.7)

31589 (100.0)
Control I (n, \%) 126356

$6112(4.8)$

19104 (15.1)

22920 (18.1)

18664 (14.8)

$17692(14.0)$

17784 (14.1)

13668 (10.8)

7224 (5.7)

3188 (2.5)

40676 (32.2)

$85680(67.8)$

22768 (18.0)

18792 (14.9)

20940 (16.6)

26296 (20.8)

37560 (29.7)

48900 (38.7)

77456 (61.3)

123330 (97.6)

$466(0.4)$

$482(0.4)$

2078 (1.6)

$0.025 \dagger$

$3158(2.5)$

45410 (35.9)

33879 (26.8)

39667 (31.4)

4242 (3.4)

110973 (87.8)

15383 (12.2)

104041 (82.3)

22315 (17.7)

25433 (20.1)

$0(0.0)$

1.000

1.000

$<0.001 \dagger$

$<0.001 \dagger$

\section{Cohort 2}

\section{Rheumatoid}

P value arthritis (n, \%)

9287

Control II (n, \%) P value

1.000

$\begin{array}{ll}374(4.0) & 1496(4.0) \\ 1253(13.5) & 5012(13.5) \\ 2095(22.6) & 8380(22.6) \\ 1718(18.5) & 6872(18.5) \\ 1419(15.3) & 5676(15.3) \\ 1204(13.0) & 4816(13.0) \\ 761(8.2) & 3044(8.2) \\ 351(3.8) & 1404(3.8) \\ 112(1.2) & 448(1.2)\end{array}$

1.000

$2625(28.3) \quad 10500(28.3)$

$6662(71.7) \quad 26648(71.7)$

\begin{tabular}{llll} 
& $6662(71.7)$ & $26648(71.7)$ & \\
1.000 & & & 1.000 \\
& $1569(16.9)$ & $6276(16.9)$ & \\
& $1267(13.6)$ & $5068(13.6)$ & \\
& $1548(16.7)$ & $6192(16.7)$ & \\
& $1969(21.2)$ & $7876(21.2)$ & \\
& $2934(31.6)$ & $11736(31.6)$ & \\
1.000 & & & 1.000 \\
\hline & $3738(40.3)$ & $14952(40.3)$ & \\
& $5549(59.8)$ & $22196(59.8)$ & \\
& & & \\
& $9116(98.2)$ & $36383(97.9)$ & \\
& $17(0.2)$ & $113(0.3)$ & \\
& $29(0.3)$ & $120(0.3)$ & \\
& $125(1.4)$ & $532(1.4)$ &
\end{tabular}

0.119

$\begin{array}{ll}169(1.8) & 814(2.2) \\ 3334(35.9) & 13079(35.2) \\ 2476(26.7) & 10134(27.3) \\ 2985(32.1) & 11878(32.0) \\ 323(3.5) & 1243(3.4)\end{array}$

0.330

$8283(89.2) \quad 33000(88.8)$

$1004(10.8) \quad 4148(11.2)$

$7890(85.0)$

30983 (83.4)

$1397(15.0) \quad 6165(16.6)$

$<0.001 \dagger \quad 2798(30.1) \quad 7769(20.9)$

$<0.001 \dagger$

$<0.001 \dagger \quad 590(6.4) \quad 1721(4.6)$
$<0.001 \dagger$

$<0.001 \dagger$

Continued 


\section{Table 1 Continued}

\begin{tabular}{|c|c|c|c|c|c|c|}
\hline \multirow[b]{2}{*}{ Characteristics } & \multicolumn{3}{|l|}{ Cohort 1} & \multicolumn{3}{|l|}{ Cohort 2} \\
\hline & Migraine (n, \%) & Control I (n, \%) & $P$ value & $\begin{array}{l}\text { Rheumatoid } \\
\text { arthritis }(n, \%)\end{array}$ & Control II (n, \%) & $P$ value \\
\hline With aura & $2287(7.2)$ & $0(0.0)$ & $<0.001 \dagger$ & $40(0.4)$ & $114(0.3)$ & 0.063 \\
\hline Without aura & $29302(92.8)$ & $0(0.0)$ & $<0.001 \dagger$ & $550(5.9)$ & $1607(4.3)$ & $<0.001 \dagger$ \\
\hline Rheumatoid arthritis & $640(2.0)$ & $1709(1.4)$ & $<0.001 \dagger$ & $9287(100.0)$ & $0(0.0)$ & $<0.001 \dagger$ \\
\hline
\end{tabular}

${ }^{*} \mathrm{CCl}$ was calculated without rheumatic diseases.

$+\chi^{2}$ test, significance at $\mathrm{p}<0.05$.

$\mathrm{BMI}$, body mass index; $\mathrm{CCl}$, Charlson Comorbidity Index.

In all subgroup analyses, higher adjusted $\mathrm{HRs}$ for RA were observed in the migraine group (each $\mathrm{p}<0.05$, table 3 ). The adjusted HR was 1.46 (95\% CI=1.33 to 1.60$)$ in all participants, $2.40(95 \% \mathrm{CI}=1.72$ to 3.36$)$ in $<60$-year-old men, $1.45(95 \% \mathrm{CI}=1.28$ to 1.64$)$ in $<60$-year-old women, 1.76 (95\% CI $=1.30$ to 2.39$)$ in $\geq 60$-year-old men and 1.25 (95\% $\mathrm{CI}=1.06$ to 1.49$)$ in $\geq 60$-year-old women. The adjusted HR was $1.35(95 \% \mathrm{CI}=1.19$ to 1.53$)$ in the low-income group and 1.58 (95\% CI=1.39 to 1.80) in the high-income group. Both urban and rural categories in the migraine group had higher adjusted HRs for RA.

\section{Cohort 2}

The results of the 1:4 matching yielded 9287 RA patients and 37148 control II participants (table 1 and figure 1). The mean follow-up time from the index date to the last date (31 December 2013) or date of death was approximately the same in both the RA (78.4 months, $\mathrm{SD}=37.3$ ) and control II groups (78.3 months, $\mathrm{SD}=37.4)$. The interval from the index date to the diagnosis of migraine was 41.4 months $(\mathrm{SD}=31.1)$ in the $\mathrm{RA}$ group and 40.4 months $(\mathrm{SD}=31.6)$ in the control II group.

The incidence of migraine was higher in the RA group $(6.4 \%(590 / 9287))$ than in the control II group $(4.6 \%$ (1721/37 148), $\mathrm{p}<0.001$, table 1$)$. The general characteristics (age, sex, income and region of residence) of the participants were the same after matching $(p=1.000)$. The adjusted HR for migraine without aura in the RA group was 1.35 (95\% $\mathrm{CI}=1.23$ to $1.49, \mathrm{p}<0.001$, table 2 and figure 2). The adjusted HR for migraine with aura in the RA group was 1.36 (95\% CI=0.95 to $1.96, \mathrm{p}=0.094)$.

In subgroup analyses, higher adjusted HRs for migraine were observed in the RA group, except in $\geq 60$-year-old

Table 2 Crude and adjusted HRs $(95 \% \mathrm{Cl})$ in cohorts 1 and 2

\begin{tabular}{|c|c|c|c|c|c|}
\hline \multirow{2}{*}{ Characteristics } & & \multicolumn{4}{|l|}{ HR } \\
\hline & & Crude* & $P$ value & Adjusted $^{*} \dagger$ & $P$ value \\
\hline \multicolumn{6}{|l|}{ Cohort 1} \\
\hline & Migraine & 1.32 (0.97 to 1.78 ) & 0.078 & 1.23 (0.91 to 1.67$)$ & 0.183 \\
\hline & Control I & 1.00 & & 1.00 & \\
\hline & Migraine & 1.52 (1.38 to 1.67 ) & $<0.001 \ddagger$ & 1.48 (1.34 to 1.63$)$ & $<0.001 \neq$ \\
\hline & Control I & 1.00 & & 1.00 & \\
\hline \multicolumn{6}{|l|}{ Cohort 2} \\
\hline \multicolumn{6}{|c|}{ HR for migraine with aura } \\
\hline & RA & 1.40 (0.98 to 2.01$)$ & 0.065 & 1.36 (0.95 to 1.96$)$ & 0.094 \\
\hline & RA & 1.38 (1.26 to 1.53$)$ & $<0.001 \ddagger$ & 1.35 (1.23 to 1.49$)$ & $<0.001 \neq$ \\
\hline & Control II & 1.00 & & 1.00 & \\
\hline
\end{tabular}

*Stratified model for age, sex, income and region of residence.

†Adjusted model for autoimmune disease, Charlson Comorbidity Index (except rheumatoid diseases), obesity (body mass index), smoking and alcohol intake histories.

$\ddagger$ Cox-proportional hazard regression model, significance at $p<0.05$.

$\mathrm{RA}$, rheumatoid arthritis. 


\section{Cohort 1}

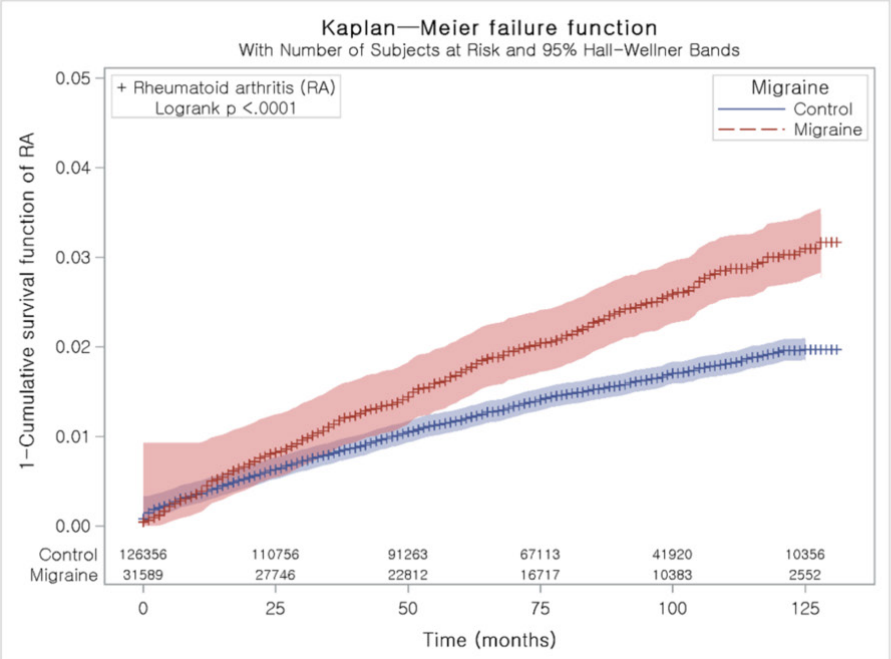

\section{Cohort 2}

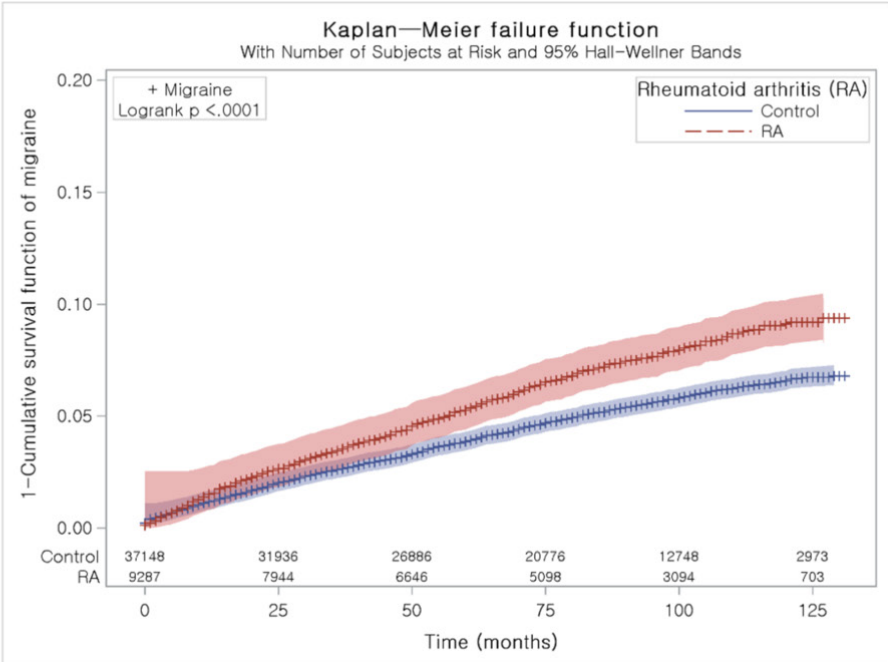

Figure 2 Kaplan-Meier survival analysis. Cohort 1: The group with migraine had a higher cumulative proportion of patients with RA than did the control I group. Cohort 2: The group with RA had a higher cumulative proportion of patients with migraine than did the control II group. RA, rheumatoid arthritis.

men (each $\mathrm{p}<0.05$, table 4$)$. The adjusted HR was 1.35 $(95 \% \mathrm{CI}=1.23$ to 1.49$)$ in all participants, $1.87(95 \%$ $\mathrm{CI}=1.32$ to 2.66$)$ in $<60$-year-old men, $1.40(95 \% \mathrm{CI}=1.23$ to 1.59$)$ in $<60$-year-old women and $1.24(95 \% \mathrm{CI}=1.05$ to $1.46)$ in $\geq 60$-year-old women. The adjusted HRs were 1.38 $(95 \% \mathrm{CI}=1.21$ to 1.57$)$ in the low-income group and 1.33 (95\% CI $=1.16$ to 1.53 ) in the high-income group. Both urban and rural categories in the RA group had higher adjusted HRs for migraine.

\section{DISCUSSION}

This study showed a bidirectional association between migraine and RA in an adult population. The HR for RA was 1.46 in the migraine patients compared with control participants. In the subgroup analyses according to age, sex, income and region of residence, the risk of RA was consistently higher in migraine patients than in the controls. Migraineurs and control I participants were of the same age composition because an age-adjusted model was used in the analysis. The risk of migraine was 1.35 times higher in RA patients than in non-RA control participants. In the age, sex, income and region of residence subgroup analyses, RA patients had a consistently higher risk of migraine except among men aged $>60$ years. In addition, Kaplan-Meier survival analysis showed that the cumulative proportion of patients with RA increased over time in the group with migraines, and the cumulative proportion of patients with migraine also increased over time in the group with RA.

In our study, the prevalence of migraine was approximately 7.5\% (38 524/514 866). Approximately 7.6\% of migraine patients had an aura, which was lower than that reported in other studies. ${ }^{24}$ Most subgroup analyses showed a correlation between migraine and RA in this study. However, RA was not associated with an increased risk of migraine in men aged $>60$ years. This result may be related to the age-specific and sex-specific prevalence of migraine. The prevalence of migraine is higher in women than in men, ${ }^{12526}$ and the most common age group affected by migraine is $25-55$ years, after which the prevalence decreases. ${ }^{1}$ Considering that our study only analysed participants aged $>40$ years, and the prevalence of migraine in Korea peaks at the ages of 19-29 years for men and 40-49 years for women, ${ }^{27}$ it is not surprising that an increased risk of migraine was not found in male RA patients aged $>60$ years. Rather, the possibility that the late-onset migraine mimics were misclassified as migraine with or without aura cannot be ruled out. ${ }^{28}$

Only a few previous studies have reported an association between migraine and RA. In a previous UK study assessing the prevalence of migraine in patients with rheumatic disorders, migraine was diagnosed in $12 \%$ of patients with RA. However, the prevalence of migraine was evaluated with a questionnaire, and there was little difference in the prevalence of migraine between the RA and control groups. ${ }^{11}$ Kalaydjian $e t a l^{10}$ reported that patients with RA were significantly more likely to be diagnosed with severe headaches or migraine $(\mathrm{OR}=1.95,95 \%$ CI 1.68 to 2.25). However, this study was limited by the use of a cross-sectional design. In a Danish study, the incidence of patients with RA was significantly higher in the migraine group than in the group without migraine $(\mathrm{OR}=2.09$, $95 \%$ CI 1.41 to 3.10$).{ }^{29}$ Wang et al, in a longitudinal study, showed a unidirectional association and reported that patients with migraines had a relatively high risk of developing RA. The mean age values of the sample population were 48.3 years $(\mathrm{SD}=15.5)$ in the migraine group and 48.5 years $(\mathrm{SD}=15.8)$ in the non-migraine group. ${ }^{9}$ In cohort 1 , the mean ages were $59.4(\mathrm{SD}=10.2)$ years in the migraine group and $59.3(\mathrm{SD}=10.2)$ years in the control I group. In 
Table 3 Crude and adjusted HRs $(95 \% \mathrm{Cl}$ ) of migraine (independent variable) for rheumatoid arthritis (dependent variable) according to age, sex, income and region of residence (cohort 1)

\begin{tabular}{|c|c|c|c|c|}
\hline \multirow[b]{2}{*}{ Characteristics } & \multicolumn{4}{|c|}{ HRs for rheumatoid arthritis } \\
\hline & Crude* $^{*}$ & $P$ value & Adjusted $^{*} \dagger$ & $P$ value \\
\hline \multicolumn{5}{|c|}{ Total participants $(n=157945)$} \\
\hline Migraine & $1.50(1.37$ to 1.64$)$ & $<0.001 \ddagger$ & $1.46(1.33$ to 1.60$)$ & $<0.001$ \\
\hline Control I & 1.00 & & 1.00 & \\
\hline \multicolumn{5}{|c|}{ Age $<60$ years, men $(n=25925)$} \\
\hline Migraine & 2.48 (1.78 to 3.45$)$ & $<0.001 \ddagger$ & 2.40 (1.72 to 3.36$)$ & $<0.001$ \\
\hline Control I & 1.00 & & 1.00 & \\
\hline \multicolumn{5}{|c|}{ Age $<60$ years, women $(n=57575)$} \\
\hline Migraine & 1.49 (1.32 to 1.69$)$ & $<0.001 \ddagger$ & 1.45 (1.28 to 1.64$)$ & $<0.001$ \\
\hline Control I & 1.00 & & 1.00 & \\
\hline \multicolumn{5}{|c|}{ Age $\geq 60$ years, men $(n=24920)$} \\
\hline Migraine & 1.81 (1.33 to 2.44$)$ & $<0.001 \ddagger$ & 1.76 (1.30 to 2.39$)$ & $<0.001$ \\
\hline Control I & 1.00 & & 1.00 & \\
\hline \multicolumn{5}{|c|}{ Age $\geq 60$ years, women $(n=49525)$} \\
\hline Migraine & 1.28 (1.08 to 1.52$)$ & $0.004 \ddagger$ & 1.25 (1.06 to 1.49$)$ & 0.009 \\
\hline Control I & 1.00 & & 1.00 & \\
\hline \multicolumn{5}{|c|}{ Low income $(n=78$ 125) } \\
\hline Migraine & 1.39 (1.22 to 1.58$)$ & $<0.001 \ddagger$ & 1.35 (1.19 to 1.53$)$ & $<0.001$ \\
\hline Control I & 1.00 & & 1.00 & \\
\hline \multicolumn{5}{|c|}{ High income $(n=79820)$} \\
\hline Migraine & $1.63(1.43$ to 1.85$)$ & $<0.001 \ddagger$ & $1.58(1.39$ to 1.80$)$ & $<0.001$ \\
\hline Control I & 1.00 & & 1.00 & \\
\hline \multicolumn{5}{|l|}{ Urban $(n=61125)$} \\
\hline Migraine & 1.53 (1.31 to 1.78$)$ & $<0.001 \ddagger$ & 1.47 (1.27 to 1.72$)$ & $<0.001$ \\
\hline Control I & 1.00 & & 1.00 & \\
\hline \multicolumn{5}{|l|}{ Rural ( $n=96820)$} \\
\hline Migraine & 1.49 (1.33 to 1.67$)$ & $<0.001 \ddagger$ & 1.45 (1.29 to 1.62$)$ & $<0.001$ \\
\hline Control I & 1.00 & & 1.00 & \\
\hline
\end{tabular}

*Stratified model for age, sex, income and region of residence.

†Adjusted model for autoimmune disease, Charlson Comorbidity Index (except rheumatoid diseases), obesity (body mas index), smoking and alcohol intake histories.

$\ddagger$ Cox-proportional hazard regression model, significance at $p<0.05$.

cohort 2, the mean ages were $58.3(\mathrm{SD}=9.1)$ years in the RA group and $58.2(\mathrm{SD}=9.2)$ years in the control II group.

This national cohort study is the first to show a bidirectional association between migraine and RA. Owing to the availability of a large cohort, we were able to include a randomly selected control group that was matched for age, sex, income and region of residence. As these health claim data from the Korean NHIS are affected by access to medical care, which in turn is affected by socioeconomic status, it is important to match participants based on socioeconomic factors such as income and region of residence. We adjusted for CCI scores, which are based on age and comorbidities, by surveying the medical records; the CCI is used to predict 1-year mortality in internal medicine patients. ${ }^{30}$ In addition to the CCI scores, BMI, smoking, alcohol consumption and autoimmune disease history, which are factors that could affect the relationship between migraine and RA, were used for adjustment. Unlike in a previous study, ${ }^{9}$ migraines were subcategorised according to the presence or absence of an aura in our study.

Migraine and RA were diagnosed by physicians two or more times in our study. Migraine was classified according to the presence or absence of an aura based on the ICD-10 codes (G43, G431). Unlike in previous studies that used questionnaires, in which the prevalence of migraine could have been affected by recall bias, ${ }^{27}$ our study used relatively accurate inclusion criteria. To increase the accuracy of the diagnosis of RA, prescriptions for a biologic agent or any DMARD were used as a criterion. Because 
Table 4 Crude and adjusted HRs $(95 \% \mathrm{Cl})$ of rheumatoid arthritis (independent variable) for migraine (dependent variable) according to age, sex, income and region of residence (cohort 2)

\begin{tabular}{|c|c|c|c|c|}
\hline \multirow[b]{2}{*}{ Characteristics } & \multicolumn{4}{|l|}{ HRs for migraine } \\
\hline & Crude* $^{*}$ & $P$ value & Adjusted $^{*} \dagger$ & $P$ value \\
\hline \multicolumn{5}{|c|}{ Total participants $(n=46435)$} \\
\hline RA & 1.39 (1.26 to 1.52$)$ & $<0.001 \ddagger$ & 1.35 (1.23 to 1.49$)$ & $<0.001 \ddagger$ \\
\hline Control II & 1.00 & & 1.00 & \\
\hline \multicolumn{5}{|c|}{ Age $<60$ years old, men $(n=7015)$} \\
\hline RA & 1.98 (1.39 to 2.80$)$ & $<0.001 \ddagger$ & 1.87 (1.32 to 2.66$)$ & $0.001 \neq$ \\
\hline Control II & 1.00 & & 1.00 & \\
\hline \multicolumn{5}{|c|}{ Age $<60$ years old, women $(n=20185)$} \\
\hline RA & 1.44 (1.27 to 1.64$)$ & $<0.001 \ddagger$ & 1.40 (1.23 to 1.59$)$ & $<0.001 \ddagger$ \\
\hline Control II & 1.00 & & 1.00 & \\
\hline \multicolumn{5}{|c|}{ Age $\geq 60$ years, men $(n=6110)$} \\
\hline RA & 1.19 (0.84 to 1.70$)$ & 0.328 & $1.16(0.81$ to 1.65$)$ & 0.418 \\
\hline Control II & 1.00 & & 1.00 & \\
\hline \multicolumn{5}{|c|}{ Age $\geq 60$ years, women $(n=13125)$} \\
\hline RA & $1.26(1.07$ to 1.48$)$ & $0.006 \ddagger$ & 1.24 (1.05 to 1.46$)$ & $0.012 \ddagger$ \\
\hline Control II & 1.00 & & 1.00 & \\
\hline \multicolumn{5}{|c|}{ Low income $(n=21920)$} \\
\hline RA & 1.41 (1.24 to 1.61$)$ & $<0.001 \ddagger$ & $1.38(1.21$ to 1.57$)$ & $<0.001 \ddagger$ \\
\hline Control II & 1.00 & & 1.00 & \\
\hline \multicolumn{5}{|c|}{ High income $(n=24515)$} \\
\hline RA & $1.36(1.19$ to 1.56$)$ & $<0.001 \ddagger$ & 1.33 (1.16 to 1.53$)$ & $<0.001 \ddagger$ \\
\hline Control II & 1.00 & & 1.00 & \\
\hline \multicolumn{5}{|l|}{ Urban $(n=18690)$} \\
\hline RA & $1.36(1.17$ to 1.58$)$ & $<0.001 \ddagger$ & $1.32(1.13$ to 1.54$)$ & $<0.001 \ddagger$ \\
\hline Control II & 1.00 & & 1.00 & \\
\hline \multicolumn{5}{|l|}{ Rural (n=27 745) } \\
\hline RA & 1.41 (1.25 to 1.58$)$ & $<0.001 \ddagger$ & 1.38 (1.22 to 1.55$)$ & $<0.001 \ddagger$ \\
\hline Control II & 1.00 & & 1.00 & \\
\hline
\end{tabular}

*Stratified model for age, sex, income and region of residence.

†Adjusted model for autoimmune disease, Charlson Comorbidity Index (except rheumatoid diseases), obesity (body mass index), smoking and alcohol intake histories.

$\ddagger$ Cox-proportional hazard regression model, significance at $\mathrm{p}<0.05$.

$\mathrm{RA}$, rheumatoid arthritis.

prevalence varies by ethnicity and residential area, there may be differences in prevalence among studies.

The possible shared pathophysiological mechanisms between migraine and RA are still unclear. With the development of migraine pathophysiology, migraine is not just vascular headache, but is recognised as complex and various neurological dysfunctions. ${ }^{3}$ The pathophysiological theory of migraine moved from vascular theory based on mechanistic models to neuroinflammation theory, specific molecules (such as CGRP and pituitary adenylate cyclase-activating peptide) and proinflammatory substances. ${ }^{12}$ Hormonal and neurological changes trigger migraine symptoms by inducing vasodilation, the release of vascular factors, including growth factors, cytokines, nitric oxide, norepinephrine and CGRPs and interactions with endothelial cells. Vascular endothelial cells may contribute to migraine. ${ }^{13}$

RA is a systemic inflammatory disease. In RA patients, this inflammatory response is not confined to the synovial space and extends to systemic reactions, including endothelial dysfunction. ${ }^{14}$ Metabolic abnormalities and changes in intracellular levels of certain metabolites are linked with the inflammatory phenotype of immune cells associated with autoimmune diseases such as RA. ${ }^{14}$ Several immune pathways highly associated with endothelial progenitor cell (EPC) dysfunction, such as type I Interferon (IFN), Tumour necrosis factor (TNF $\alpha)$, Vascular endothelial growth factor (VEGF)/VEGF 
receptor and neutrophil-activating cytokines, are known to affect systemic conditions such as RA. The role of EPCs as mediators of crosstalk between vascular repair and immunity and the regulation of EPC levels and functions by inflammatory cytokines in systemic diseases are important. ${ }^{15}$ We hypothesised that the common pathophysiologic mechanism of inflammation, vascular endothelial cells and the immune system between migraine and RA could contribute to the bidirectional association between migraine and RA.

Comorbidities in patients with migraine and RA include depression, obesity and sleep disturbances. In particular, depression is a comorbidity that is common between migraine and RA. ${ }^{19} 31$ Cortical spreading depression in patients with migraine affects cortical neuron sensitivity and releases substances that stimulate meningeal vessels, causing the dilatation and inflammation of blood vessels known as sterile neurogenic inflammation. Impaired serotonin metabolism in migraineurs plays a major role in the pathophysiology of depression. ${ }^{32-34}$ Many studies have also found an association between RA and depression. ${ }^{35}{ }^{36}$ Peripheral inflammation associated with RA is usually associated with neural inflammation in the brain in patients with depression. ${ }^{37} 38$ Biological factors, including inflammatory pathways, appear to be important in the pathophysiology of the bidirectional association between depression and RA. ${ }^{39} 40$ Serotonin has been shown to be associated with the pathogenesis of RA. ${ }^{41}$

Obesity and sleep disturbance are also comorbidities between migraine and RA. Adipose tissue is considered a neuroendocrine organ that participates in multiple pathophysiological immune and inflammatory processes, including those underlying the development of migraine ${ }^{42}$ A recent systemic review and meta-analysis showed that the risk of migraine is elevated in obese persons. ${ }^{43}$ According to a study in Israel, obesity is significantly independently associated with RA. The mechanisms by which obesity may lead to RA are still being studied, but several potential mechanisms include chronic inflammation, vitamin $\mathrm{D}$ deficiency in patients with autoimmune diseases and sex hormones. ${ }^{44}$

The relationship between migraines and sleep is reciprocal. Sleep disturbances are important risk factors for migraine, and migraine interferes with the quality of sleep.

A study found an elevated risk of severe sleep disturbances in patients with migraine $(\mathrm{OR} 5.4,95 \% \mathrm{CI}=2$ to 15.5). ${ }^{45}$ Sleep disturbances are common in patients with RA. Patients with RA suffer from a variety of symptoms, including joint pain, that lead to a poor quality of life, and that pain is closely related to sleep disturbances. ${ }^{46}$

Some limitations of this study should be considered. In all participants, the adjusted HR for RA was 1.46 (95\% $\mathrm{CI}=1.33$ to $1.60, \mathrm{p}<0.001$ ), whereas the adjusted HR for RA in the migraine with aura group was not significant. Moreover, in a previous study, the multivariable-adjusted HR for RA in the migraine group was 1.91 (95\% CI=1.58 to 2.31$),{ }^{9}$ which was lower than the HR in our study.
Glucocorticoids are used in patients with severe migraine, and they may have affected the prevalence of RA. Glucocorticoids are a DMARD that can lead to rapid symptom improvement and disease-modifying effects in patients with RA. ${ }^{5}$ Glucocorticoids have been widely prescribed to patients with severe refractory, recurrent, and status migraine and to patients with RA. ${ }^{47}$ The detailed history of medications used for migraine could not be considered in our study.

Structural issues, such as temporomandibular joint (TMJ) destruction and atlantoaxial instability, can trigger migraine attacks in RA patients. RA is a systemic inflammatory disease that affects the articular surfaces of the joints, including the TMJ. TMJ disorder typically includes bilateral pain, tenderness and swelling around the deep preauricular area. ${ }^{48}$ RA patients also have upper cervical spine instability, which can include neck pain and occipital headache. RA alters the stability of the cervical spine through a combination of periarticular bone loss and juxta-articular bone erosions and osteoporosis due to inflammation of the synovial membrane. ${ }^{49} 50$ The diagnosis of RA is subject to relatively strict diagnostic criteria, and the algorithm for identifying RA in the National Health Insurance Claims database has been validated in previous studies; however, the diagnosis of migraine tends to rely on symptoms. It is possible that the risk of migraine in RA was overestimated because some migraine mimics were misclassified as migraines.

We have included information on lifestyle factors that could influence the relationship between migraine and RA. However, other socioeconomic factors, such as occupation, physical inactivity, diet and nutrition, were not considered in this study. There were no missing data from diagnosed patients, but it should be taken into consideration that this study may not have included asymptomatic or untreated patients. There was also limited information on disease severity for migraine and RA. Considering the prevalence of migraine in Korea and the fact that newonset migraine in the elderly population is rare, our study is limited by not including patients $<40$ years of age.

\section{CONCLUSION}

Two longitudinal follow-up studies using a Korean national cohort showed a bidirectional association between migraine and RA, in which migraine increases the risk of RA, and RA is also associated with an increased risk of migraine.

\section{Author affiliations}

${ }^{1}$ Department of Neurology, Hallym University Sacred Heart Hospital, Anyang, The Republic of Korea

${ }^{2}$ Department of Orthopedic Surgery, Yonsei University Wonju College of Medicine, Wonju, The Republic of Korea

${ }^{3}$ Department of Neurology, Kangdong Sacred Heart Hospital, Seoul, The Republic of Korea

${ }^{4}$ Department of Neurology, Chuncheon Sacred Heart Hospital, Chuncheon, The Republic of Korea

${ }^{5}$ Hallym Data Science Laboratory, Hallym University College of Medicine, Anyang, The Republic of Korea 
${ }^{6}$ Graduate School of Public Health, Seoul National University, Seoul, The Republic of Korea

${ }^{7}$ Department of Otorhinolaryngology-Head \& Neck Surgery, Hallym University College of Medicine, Anyang, The Republic of Korea

Acknowledgements We thank the Korean National Health Insurance Service for providing the data.

Contributors As the first author, YHK: wrote the manuscript. JWL, YK, JSB and YJK: analysed and interpreted the data. CM: processed the data. HGC: wrote and reviewed the manuscript. All authors participated in collection of data and they gave final approval of the version to be published.

Funding This work was supported in part by a research grant (NRF-2018R1D1A1A02085328)from the National Research Foundation (NRF) of Korea. The funders had no role in the study design, data collection and analysis, decision to publish or preparation of the manuscript.

Competing interests None declared.

Patient consent for publication Not required.

Ethics approval The ethics committee of Hallym University (2017-|102) approved the use of these data.

Provenance and peer review Not commissioned; externally peer reviewed.

Data availability statement Data are available in a public, open access repository. The data underlying this article are available at https://nhiss.nhis.or.kr and can be accessed after approval by the Institutional Review Board with some payment.

Supplemental material This content has been supplied by the author(s). It has not been vetted by BMJ Publishing Group Limited (BMJ) and may not have been peer-reviewed. Any opinions or recommendations discussed are solely those of the author(s) and are not endorsed by BMJ. BMJ disclaims all liability and responsibility arising from any reliance placed on the content. Where the content includes any translated material, BMJ does not warrant the accuracy and reliability of the translations (including but not limited to local regulations, clinical guidelines, terminology, drug names and drug dosages), and is not responsible for any error and/or omissions arising from translation and adaptation or otherwise.

Open access This is an open access article distributed in accordance with the Creative Commons Attribution Non Commercial (CC BY-NC 4.0) license, which permits others to distribute, remix, adapt, build upon this work non-commercially, and license their derivative works on different terms, provided the original work is properly cited, appropriate credit is given, any changes made indicated, and the use is non-commercial. See: http://creativecommons.org/licenses/by-nc/4.0/.

\section{ORCID iDs}

Yoo Hwan Kim http://orcid.org/0000-0002-9532-5769

Hyo Geun Choi http://orcid.org/0000-0003-1655-9549

\section{REFERENCES}

1 Dodick DW. Migraine. Lancet 2018;391:1315-30.

2 Stovner L, Hagen K, Jensen R, et al. The global burden of headache: a documentation of headache prevalence and disability worldwide. Cephalalgia 2007;27:193-210.

3 Charles A. The pathophysiology of migraine: implications for clinical management. Lancet Neurol 2018;17:174-82.

4 Peters GL. Migraine overview and summary of current and emerging treatment options. Am J Manag Care 2019;25:S23-34.

5 Smolen JS, Aletaha D, Mclnnes IB. Rheumatoid arthritis. The Lancet 2016;388:2023-38.

6 DeQuattro K, Imboden JB. Neurologic manifestations of rheumatoid arthritis. Rheum Dis Clin North Am 2017;43:561-71.

7 van der Woude D, van der Helm-van Mil AHM. Update on the epidemiology, risk factors, and disease outcomes of rheumatoid arthritis. Best Pract Res Clin Rheumatol 2018;32:174-87.

8 Jeong H, Baek SY, Kim SW, et al. Comorbidities of rheumatoid arthritis: results from the Korean National health and nutrition examination survey. PLoS One 2017;12:e0176260.

9 Wang Y-C, Huang Y-P, Wang M-T, et al. Increased risk of rheumatoid arthritis in patients with migraine: a population-based, propensity score-matched cohort study. Rheumatol Int 2017;37:273-9.

10 Kalaydjian A, Merikangas K. Physical and mental comorbidity of headache in a nationally representative sample of US adults. Psychosom Med 2008;70:773-80.
11 Pal B, Gibson C, Passmore J, et al. A study of headaches and migraine in Sjögren's syndrome and other rheumatic disorders. Ann Rheum Dis 1989;48:312-6.

12 Cavestro C, Ferrero M, Mandrino S, et al. Novelty in inflammation and immunomodulation in migraine. Curr Pharm Des 2019;25:2919-36.

13 Jacobs B, Dussor G. Neurovascular contributions to migraine: moving beyond vasodilation. Neuroscience 2016;338:130-44.

14 Dimitroulas T, Hodson J, Sandoo A, et al. Endothelial injury in rheumatoid arthritis: a crosstalk between dimethylarginines and systemic inflammation. Arthritis Res Ther 2017;19:32.

15 Rodríguez-Carrio J, López P, Suárez A. Endothelial progenitor cells as mediators of the crosstalk between vascular repair and immunity: lessons from systemic autoimmune diseases. Curr Med Chem 2018;25:4478-96.

16 Kim SY, Min C, Oh DJ, et al. Tobacco smoking and alcohol consumption are related to benign parotid tumor: a nested casecontrol study using a national health screening cohort. Clin Exp Otorhinolaryngol 2019;12:412-9.

17 Kim SK, Hong SM, Park I-S, et al. Association between migraine and benign paroxysmal positional vertigo among adults in South Korea. JAMA Otolaryngol Head Neck Surg 2019;145:307-12.

18 Lee S-Y, Lim J-S, Oh DJ, et al. Risk of ischaemic stroke in patients with migraine: a longitudinal follow-up study using a national sample cohort in South Korea. BMJ Open 2019;9:e027701.

19 Kim SY, Chanyang M, Oh DJ, et al. Association between depression and rheumatoid arthritis: two longitudinal follow-up studies using a national sample cohort. Rheumatology 2020;59:1889-97.

20 Sung Y-K, Cho S-K, Choi C-B, et al. Prevalence and incidence of rheumatoid arthritis in South Korea. Rheumatol Int 2013;33:1525-32.

21 Cho S-K, Sung Y-K, Choi C-B, et al. Development of an algorithm for identifying rheumatoid arthritis in the Korean National health insurance claims database. Rheumatol Int 2013;33:2985-92.

22 WHO/IASO/IOTR. The Asia-Pacific Perespective: redefining obesity and its treatment. Health Communications Australia Pty Ltd 2000.

23 Quan $\mathrm{H}$, Li B, Couris CM, et al. Updating and validating the Charlson comorbidity index and score for risk adjustment in hospital discharge Abstracts using data from 6 countries. Am J Epidemiol 2011;173:676-82.

24 Lin Q-F, Xia Q-Q, Zeng Y-L, et al. Prevalence of migraine in Han Chinese of Fujian Province: an epidemiological study. Medicine 2018;97:e13500.

25 Vetvik KG, MacGregor EA. Sex differences in the epidemiology, clinical features, and pathophysiology of migraine. Lancet Neurol 2017;16:76-87.

26 Lipton RB, Bigal ME, Diamond M, et al. Migraine prevalence, disease burden, and the need for preventive therapy. Neurology 2007;68:343-9.

27 Kim B-K, Chu MK, Lee TG, et al. Prevalence and impact of migraine and tension-type headache in Korea. J Clin Neurol 2012;8:204-11.

28 Angus-Leppan H. Migraine: mimics, borderlands and chameleons. Pract Neurol 2013;13:308-18.

29 Le H, Tfelt-Hansen P, Russell MB, et al. Co-Morbidity of migraine with somatic disease in a large population-based study. Cephalalgia 2011;31:43-64.

30 Charlson ME, Pompei P, Ales KL, et al. A new method of classifying prognostic comorbidity in longitudinal studies: development and validation. J Chronic Dis 1987;40:373-83.

31 Bigal ME, Lipton RB. The epidemiology, burden, and comorbidities of migraine. Neurol Clin 2009;27:321-34.

32 Ward TN. Migraine diagnosis and pathophysiology. Continuum 2012;18:753-63.

33 Saengjaroentham C, Supornsilpchai W, Ji-Au W, et al. Serotonin depletion can enhance the cerebrovascular responses induced by cortical spreading depression via the nitric oxide pathway. Int $J$ Neurosci 2015;125:130-9.

34 Danese E, Montagnana M, Lippi G. Platelets and migraine. Thromb Res 2014;134:17-22.

35 Jamshidi A-R, Banihashemi AT, Paragomi P, et al. Anxiety and depression in rheumatoid arthritis: an epidemiologic survey and investigation of clinical correlates in Iranian population. Rheumatol Int 2016;36:1119-25.

36 Sheehy C, Murphy E, Barry M. Depression in rheumatoid arthritis-underscoring the problem. Rheumatology 2006;45:1325-7.

37 Nerurkar L, Siebert S, Mclnnes IB, et al. Rheumatoid arthritis and depression: an inflammatory perspective. Lancet Psychiatry 2019;6:164-73.

38 Liu Y, Ho RC-M, Mak A. Interleukin (IL)-6, tumour necrosis factor alpha (TNF- $\alpha$ ) and soluble interleukin-2 receptors (sIL-2R) are elevated in patients with major depressive disorder: a meta-analysis and meta-regression. J Affect Disord 2012;139:230-9. 
39 Vallerand IA, Lewinson RT, Frolkis AD, et al. Depression as a risk factor for the development of rheumatoid arthritis: a populationbased cohort study. RMD Open 2018;4:e000670.

40 Vallerand IA, Patten SB, Barnabe C. Depression and the risk of rheumatoid arthritis. Curr Opin Rheumatol 2019;31:279-84.

41 Zeller J, Weissbarth E, Baruth B, et al. Serotonin content of platelets in inflammatory rheumatic diseases. Correlation with clinical activity. Arthritis Rheum 1983;26:532-40.

42 Peterlin BL, Rapoport AM, Kurth T. Migraine and obesity: epidemiology, mechanisms, and implications. Headache 2010;50:631-48.

43 Gelaye B, Sacco S, Brown WJ, et al. Body composition status and the risk of migraine: a meta-analysis. Neurology 2017;88:1795-804

44 Dar L, Tiosano S, Watad A, et al. Are obesity and rheumatoid arthritis interrelated? Int J Clin Pract 2018;72. doi:10.1111/ijcp.13045. [Epub ahead of print: 1212 2017].
45 Ødegård SS, Engstrøm M, Sand T, et al. Associations between sleep disturbance and primary headaches: the third Nord-Trøndelag health study. J Headache Pain 2010;11:197-206.

46 Goes ACJ, Reis LAB, Silva MBG, et al. Rheumatoid arthritis and sleep quality. Rev Bras Reumatol Engl Ed 2017;57:294-8.

47 Woldeamanuel YW, Rapoport AM, Cowan RP. What is the evidence for the use of corticosteroids in migraine? Curr Pain Headache Rep 2014; $18: 464$

48 Savtekin G, Sehirli AO. Rheumatoid arthritis in temporo-mandibular joint: a review. Niger J Clin Pract 2018;21:1243-6.

49 Bayer E, Elliott R, Bang M, et al. Atlantoaxial instability in a patient with neck pain and rheumatoid arthritis. J Spinal Cord Med 2021:44:433-6. doi:10.1080/10790268.2019.1580859

50 Shlobin NA, Dahdaleh NS. Cervical spine manifestations of rheumatoid arthritis: a review. Neurosurg Rev 2020. doi:10.1007/ s10143-020-01412-1. [Epub ahead of print: 10 Oct 2020]. 